\title{
FACTORS MAINTAINING CEREBRAL CIRCULATION DURING GRAVITATIONAL STRESS
}

\author{
BY JAMES P. HENRY, OTTO H. GAUER, SEYMOUR S. KETY,1 AND \\ KURT KRAMER 2 \\ (From the Aero Medical Laboratory, Air Materiel Command, Wright-Patterson Air Force Base, \\ Dayton, Ohio)
}

(Submitted for publication July 27, 1950; accepted, December 21, 1950)

\section{INTRODUCTION}

The stresses developed during flight may make certain physiological mechanisms clear which would otherwise be difficult to demonstrate. This report is concerned with a condition induced by forces peculiar to high speed aircraft, but the results can be applied to the cerebral circulation during the more familiar stresses induced by gravity in the erect position. Amaurosis fugax, or aviator's blackout (1), occurs in normal men when they are exposed in the upright seated posture to centrifugal forces acting for more than five seconds in the direction head to buttocks. Commencing at 3 to 4 gravity units as a dimming of vision most noticeable in the peripheral field, at 4 to 5 gravity units it progresses to temporary blindness and finally, at slightly higher levels, unconsciousness occurs. Lambert (2) has shown that apparently identical changes in vision can be produced by air pressure on the eye balls. By sucking on the eyes with a special mask, he prevented blackout during high accelerations. His experiment confirmed the belief that the centrifugal forces induce blackout by causing a decrease in the arterial pressure at eye level. This pressure drop results from an increase in the effective weight of the blood which increases the effective length of the column above the heart. Since the pressure is proportional to the acceleration, at 5 gravity units the normal arterial pressure becomes inadequate, for it must then raise the blood the equivalent of five times the $30 \mathrm{cms}$. distance from the heart to the head. Lambert and Wood ( 3 ) have shown that the systolic pressure at eye level during exposures producing blackout is less than $20 \mathrm{~mm}$. Hg, and they have

\footnotetext{
1 Department of Physiology, Graduate School of Medicine, University of Pennsylvania, Philadelphia.

2 School of Aviation Medicine, Randolph Air Force Base, Texas. Present address: Physiologisches Institut der Universität, Marburg.
}

observed that the pressure often falls temporarily to zero (4). Rossen, Kabat and Anderson (5) have shown that if the blood supply to the human brain is suddenly interrupted, consciousness is lost in six seconds. The circulation should, theoretically, be halted by an acceleration which reduces the mean arterial pressure at head level to near zero values. In spite of this, maintenance of consciousness has been reported during a blackout of three minutes duration on the human centrifuge (6). This continued alertness for periods of 30 seconds or more, in the face of a measured cerebral arterial pressure of $20 \mathrm{~mm}$. $\mathrm{Hg}$ to $30 \mathrm{~mm}$. Hg (7) is surprising. However, a survey of the clinical experiences with syncope also yielded extremely low values. Data from the observation of four different conditions were available (Table I), namely, clinical orthostatic hypotension (8-10); a phlebotomy followed by syncope (11); the use of a tilt table with amyl nitrite (12) and collapse following puncture of the brachial artery (13). The significant parameter in the assessment of blood flow is the mean pressure. Since this was not explicit in the clinical data, it was calculated from the systolic and diastolic pressures by adding $1 / 3$ of the pulse pressure to the diastolic pressure. (Table I, Column M). To make these figures comparable with the data obtained on the centrifuge mean pressure at eye level was estimated by subtracting from it the hydrostatic pressure of the fluid column between the brain and the various measuring points (Table I, Column E). The recorded values for visual symptoms, ranged about $30 \mathrm{~mm}$. $\mathrm{Hg}$ to $40 \mathrm{~mm}$. $\mathrm{Hg}$; those for syncope were approximately $20 \mathrm{~mm}$. $\mathrm{Hg}$.

These facts suggest that compensating factors are at work and that a study of cerebral circulatory competence during exposure to gravitational fields should be of interest. The nitrous oxide technique for the accurate measurement of cerebral 
blood flow in man requires a longer period than was available for applying the stress with the human centrifuge. However, since there is little storage capacity for oxygen in the small blood content of the brain tissue itself, changes of cerebral venous oxygen content will reflect circulatory changes occurring within relatively short time intervals. Kety and his associates (14) have pointed out that the reciprocal of the cerebral arterio-venous oxygen difference represents the ratio of cerebral blood flow to metabolic demand. Although it yields no information concerning either of these parameters separately, the cerebral A-V $\mathrm{O}_{2}$ does constitute a measure of the sufficiency of the cerebral circulation. It was, therefore, decided to measure the cerebral venous and arterial oxygen saturation during acceleration.

\section{METHODS}

Arterial pressures at head level were determined by a strain gauge blood pressure transmitter (15) connected by rigid walled, incollapsible vinylite tubing to a Linde- man type cannula placed in the radial artery (16). The wrist was held at head level and the gauge was firmly attached to a cap held at eye level. Thus even if the subject slumped in his seat during the acceleration, there would be no movement between the gauge and the brain. There is only $5 \mathrm{~mm}$. $\mathrm{Hg}$ difference between the mean pressures in the carotid and radial arteries of a supine man (17); therefore, it was felt that the pressure in the radial artery is a satisfactory measure of that in the cerebral vessels if due account is taken for hydrostatic effects. Since blood flow is a function of mean pressure, mean pressures were assessed. Planimetry of sample pulse curves confirms the accuracy of the calculations of mean pressure made by adding $1 / 3$ of the pulse pressure to the diastolic pressure (18).

The internal jugular vein was punctured by a needle inserted just below the mastoid process, using a 19 gauge needle. The technique was that introduced by Myerson, Halloran, and Hirsch (19) and described by Kety (20) in his recent account of the quantitative determination of cerebral blood flow in man. It results in the placement of the tip of the needle in a region just below the jugular foramen where collapse of the vein is impossible due to its bony attachment. A 2 by $3 \mathrm{cms}$. brass plate was fastened to the neck by adhesive tape and an attached clamp tightened around the needle to prevent slip-

TABLE I

Estimated mean cerebral blood pressure in $\mathrm{mm}$. Hg during syncope

\begin{tabular}{|c|c|c|c|c|c|c|c|}
\hline \multirow{2}{*}{ Author and Method } & \multirow{2}{*}{ Cause } & \multirow{2}{*}{ Case } & \multicolumn{4}{|c|}{ Blood pressure (mm. $\left.\mathrm{H}_{\mathrm{g}}\right)$} & \multirow{2}{*}{ Symptoms as described by authors } \\
\hline & & & $\mathbf{S} / \mathbf{D}$ & $\mathbf{M}^{*}$ & $E^{*}$ & $\mathrm{ME}^{*}$ & \\
\hline $\begin{array}{l}\text { Ellis and Haynes (8), } \\
\text { Riva Rocci }\end{array}$ & $\begin{array}{l}\text { Orthostatic } \\
\text { hypotension }\end{array}$ & $\begin{array}{l}1 \\
2 \\
3 \\
4 \\
5 \\
6 \mathrm{a} \\
6 \mathrm{~b}\end{array}$ & $\begin{array}{l}65 / 52 \\
62 / 46 \\
33 / 26 \\
62 / 41 \\
75 / 56 \\
56 / 44 \\
42 / 30\end{array}$ & $\begin{array}{l}56 \\
51 \\
28 \\
48 \\
62 \\
48 \\
34\end{array}$ & $\begin{array}{r}44 \\
29 \\
6 \\
24 \\
40 \\
33 \\
16\end{array}$ & 27 & $\begin{array}{l}\text { Feeling of faintness to absolute syncope } \\
\text { Blurring of vision; "all gone feeling" } \\
\text { Buzzing; blurring of vision } \\
\text { Dizziness } \\
\text { Dizziness } \\
\text { Marked dizziness } \\
\text { Marked dizziness }\end{array}$ \\
\hline $\begin{array}{l}\text { Jeffers, Montgomery } \\
\text { and Burton (9), Riva } \\
\text { Rocci }\end{array}$ & $\begin{array}{l}\text { Orthostatic } \\
\text { hypotension }\end{array}$ & $\begin{array}{l}\text { WL } \\
\text { LM } \\
\text { TM }\end{array}$ & $\begin{array}{l}50 / 45 \\
60 / 50 \\
42 / 38\end{array}$ & $\begin{array}{l}47 \\
53 \\
39\end{array}$ & $\begin{array}{l}25 \\
21 \\
17\end{array}$ & 21 & $\begin{array}{l}\text { Vertigo; fainting }++ \\
\text { Vertigo; fainting }+++ \\
\text { Vertigo; fainting }++++\end{array}$ \\
\hline $\begin{array}{l}\text { Gregory (10), Riva } \\
\text { Rocci }\end{array}$ & $\begin{array}{l}\text { Orthostatic } \\
\text { hypotension }\end{array}$ & $\begin{array}{l}1 \mathrm{a} \\
1 \mathrm{~b} \\
1 \mathrm{c}\end{array}$ & $\begin{array}{l}45 / ? \\
50 / ? \\
55 / 40\end{array}$ & 45 & 23 & 23 & $\begin{array}{l}\text { Fainting } \\
\text { Very dizzy } \\
\text { Dizzy }\end{array}$ \\
\hline $\begin{array}{l}\text { Loman and colleagues } \\
\text { (12), Tycos elastic ma- } \\
\text { nometer, carotid artery }\end{array}$ & $\begin{array}{l}\text { Sudden tilting } \\
\text { Amyl nitrite }\end{array}$ & & & $\begin{array}{l}28 \\
22\end{array}$ & $\begin{array}{l}22 \\
16\end{array}$ & 19 & $\begin{array}{l}\text { Fainting } \\
\text { Verge of syncope }\end{array}$ \\
\hline $\begin{array}{l}\text { McMicheal (11), Riva } \\
\text { Rocci }\end{array}$ & Hemorrhage & & $58 / ?$ & 20 & $<20$ ? & & Syncope \\
\hline $\begin{array}{l}\text { Rushmer (13), Hamilton } \\
\text { manometer, Riva Rocci }\end{array}$ & $\begin{array}{l}\text { Neurogenic } \\
\text { collapse }\end{array}$ & & $\begin{array}{l}65 / ? \\
45 / ?\end{array}$ & & $\begin{array}{l}<43 \\
<23\end{array}$ & & $\begin{array}{l}\text { Dizziness } \\
\text { Unconsciousness }\end{array}$ \\
\hline
\end{tabular}

* M Mean arterial pressure obtained by adding $\frac{1}{3}$ of pulse pressure to the diastolic pressure.

E Mean arterial pressure at eye level calculated by allowing for the estimated hydrostatic pressure of the vertical column between gauge and eye.

$\mathrm{ME}$ Average pressure from E.

Table of data collected from various sources showing that the mean arterial pressure can fall below $30 \mathrm{~mm}$. $\mathrm{Hg}$ before consciousness is seriously impaired, but that syncope develops at $20-25 \mathrm{~mm}$. $\mathrm{Hg}$. 
ping during the centrifuge run. Samples could be taken rapidly during the run by a series of three-way stopcocks, to each of which was attached a syringe (20). The heparinized samples were chilled until submitted for analysis of oxygen content by the Van Slyke manometric method (21). The blood was drawn by an experimenter sitting beside the subject in the cab of the centrifuge. Runs were made at accelerations ranging from 1.0 to $4.5 \mathrm{~g}$ and the force was held constant for one to two minutes at each acceleration until the blood samples had been drawn. Three trained subjects were employed. Once the needles had been inserted they were at ease. Their normal resting blood pressures give objective confirmation of their relaxation. In two subjects, four series of experiments, involving prolonged acceleration, were made and the oxygen content of 13 samples of cerebral venous blood determined at the various accelerations. In three of these series the arterial blood pressure was determined at the same time. (The possibility of equipment failure with leakage of air into the jugular vein was not ignored. The dangers of a small aeroembolism are inappreciable and the observer in the cab watched the transparent tube leading to the needle. If air leakage developed the blood would disappear from the tube. This could be seen and the needle removed at once. In practice this emergency did not occur.)

Jugular pressures were recorded by a second strain gauge transmitter also held at eye level. Both systems were flushed with heparinized saline to prevent clotting. A rapid pressure rise following a Valsalva maneuver and the presence of pulsations, which persisted in spite of digital occlusion of the jugular vein during acceleration, assured the patency of the needle and its free communication with the intracranial sinuses.

In two subjects the oxygen saturation of the blood in the jugular vein was measured continuously by drawing it through a Kramer glass cuvette oximeter (22) by a mechanically actuated syringe (23). The oximeter was calibrated by passing blood of known saturation through it. Since all the samples were drawn at the same constant speed, the flow effect, characteristic of these instruments, could be disregarded.

Changes in venous oxygen saturation will only reflect the sufficiency of the cerebral blood flow provided the arterial saturation remains essentially undisturbed. Therefore, in control experiments the oximeter was connected to the arterial cannula. Arterial saturation was measured during typical centrifuge acceleration "runs" such as $4.5 \mathrm{~g}$ for 15 seconds. It fell from $98 \%$ to $93 \%$. Since the onset of this change was delayed by more than 10 seconds, it occurred too late to affect venous oxygen saturation significantly during the period of the greatest depression of the saturation. This was during the first 10 seconds of the 15 second runs. As will be shown, the most striking result has been the maintenance of cerebral venous oxygen saturation in spite of the fall in arterial pressure induced by the gravitation. No correction has been made for a possible slight fall in arterial oxygen saturation during the higher, prolonged accelerations. However, the error resulting from this omission would only depress the apparent venous oxygen saturation and give an impression of failure of circulatory sufficiency.

During both arterial and venous oximetry, the blood accumulated in the mechanical syringe constituted an integrated sample giving the mean value of the saturation throughout the sampling period. There was a seven to eight second delay before the oximeter revealed changes in the oxygen content. This lag was due to the time taken for passage of the blood from the brain capillaries to the needle (three to four seconds) and thence to the cuvette (four seconds).

Light signals in the peripheral and central fields of vision were employed to assess the visual impairment during the runs. The responses were recorded photographically, together with the other variables under study.

\section{RESULTS}

\section{Cerebral venous oxygen content in relation to mean arterial pressures}

In Figure 1 mean arterial blood pressure at head level is compared with mean venous oxygen saturation. The pressure fell in direct proportion to the acceleration, attaining $30 \mathrm{~mm}$. $\mathrm{Hg}$ at approximately $4.0 \mathrm{~g}^{3}{ }^{3}$

The mean cerebral venous oxygen saturation stays materially unchanged in contrast with the mean arterial pressure. In fact, two of the three series actually show a slight rise in the 2 to $3 \mathrm{~g}$ range. Some fall occurs at higher accelerations but never to the critical values that would be expected in view of the fall in arterial pressure. Fast records of the behavior of the venous oxygen content during the acceleration show the same picture. Figure 2 is a typical example of three records taken of two of the subjects, showing changes in oxygen saturation in the jugular vein as recorded by direct

${ }^{3}$ In extensive studies of arterial pressure at eye level during 15 second accelerations of abrupt onset, Lambert and Wood (3) have obtained similar results. The main difference is the acceleration at which they observed visual symptoms. They found that blackout normally occurs at 4 to $5 \mathrm{~g}$ and their data indicate that the lowest systolic pressure inducing a blackout during exposure was often zero, and generally below $20 \mathrm{~mm}$. Hg. In the present study the mean arterial pressure, as measured throughout the run, was still approximately $30 \mathrm{~mm}$. $\mathrm{Hg}$ at $4.5 \mathrm{~g}$. Higher accelerations were needed to produce visual symptoms in these experiments because in order to give time for sampling, the centrifuge was accelerated gradually and the run lasted from one to two minutes. This technique elicits a full vasomotor response and consequently the arterial pressure was higher than in runs used by Wood and his associates (4). 


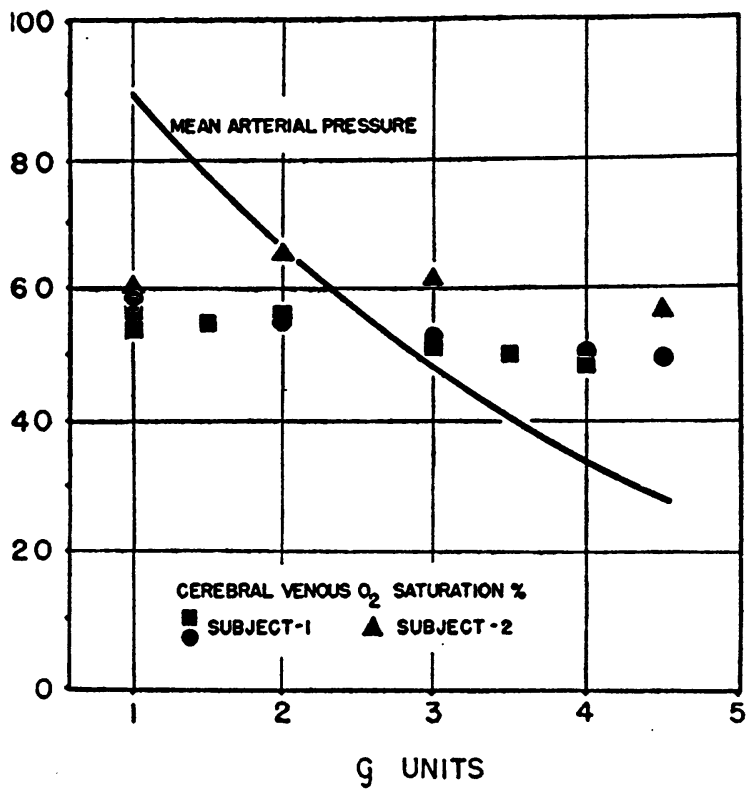

Fig. 1. Mean Arterial Pressure at Head Level Plotted against Acceleration

Ordinate: pressure in $\mathrm{mm}$. $\mathrm{Hg}$ and venous oxygen saturation per cent. Abscissa; $g$ units. Cerebral venous oxygen saturation remains essentially constant in spite of the fall in arterial pressure during the prolonged one to two minute accelerations.

oximetry. Events in the curve are delayed for seven to eight seconds by the time constants of the oximeter. After the initial increase from $50 \%$ to $55 \%$, the saturation falls to $42 \%$ at the time when the arterial pressure is lowest. The vasopressor response is associated with a rise in venous saturation which follows the behavior of the blood pressure after the acceleration ends. However, these changes in oxygen saturation are small in comparison with the great fluctuations in arterial pressure at head level.

Since the arterio-venous oxygen difference is a measure of the sufficiency of the cerebral blood supply, some compensatory effect must be responsible for its remarkable constancy in face of the changes in arterial pressure. This effect could either be vasodilatation reducing cerebral vascular resistance or a fall in venous pressure increasing the force driving the blood through the capillary bed.

\section{Pressure Measurements in the Jugular Bulb}

It seemed possible that as a result of the acceleration, a negative pressure might develop in the intracranial veins which continuously sustained cerebral blood flow and, therefore, venous oxygen saturation, by partially compensating for the marked fall in cerebral arterial pressure. In addition to animal studies using the saggittal sinus as a pressure source $(7)$, repeated measurements

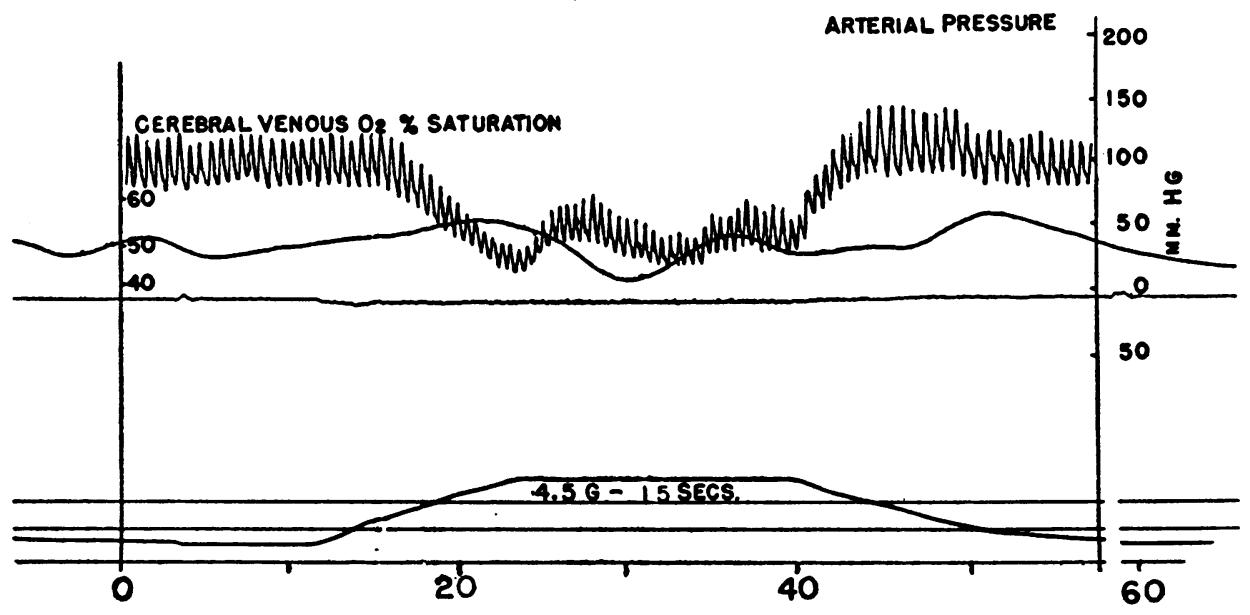

SECONDS

Fig. 2. Arterial Pressure in Subject 3 at Head Lever During a Brief 4.5 g Acceleration, LASTING 15 Seconds

Abscissa; time in seconds. Ordinate; on left: cerebral venous oxygen saturation in volumes per cent; on the right : arterial pressure in $\mathrm{mm}$. Hg. The constants of the oximeter cause a seven second delay in the response curve. 


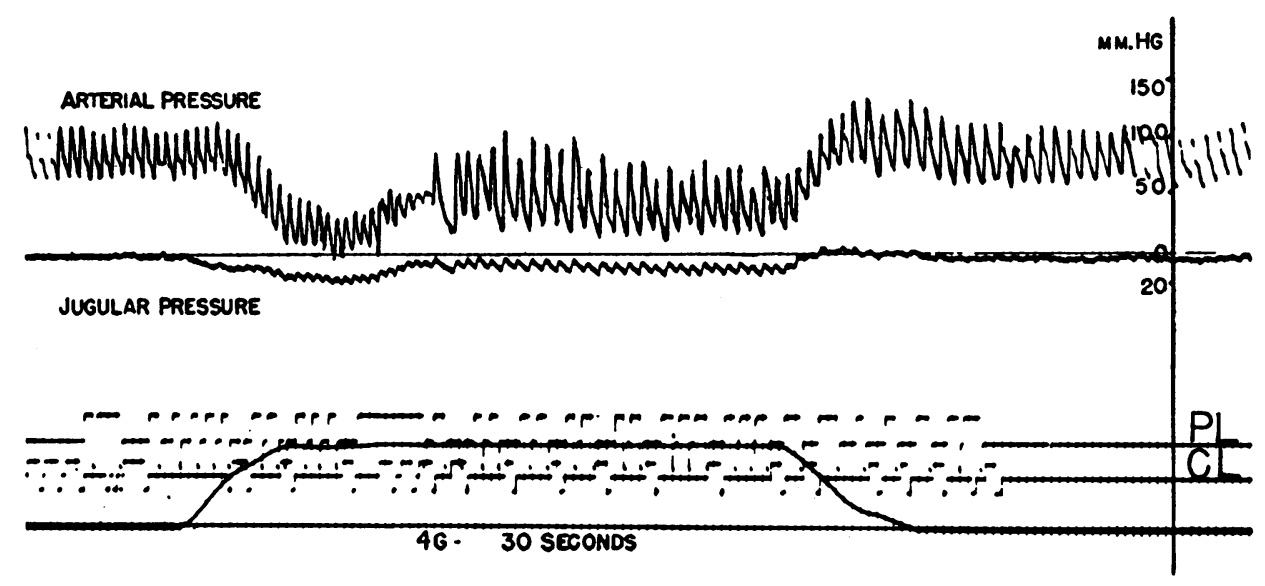

$5155 \div \mathrm{V}$

Fig. 3. Cerebral Arterial and Jugular Venous Pressures during a 30 Second Run at 4.0 g

Peripheral lights (PL) and center lights (CL) responses respectively. Note the failure to respond to the peripheral lights for a few seconds after the deepest fall in arterial pressure.

were taken at the superior jugular bulb using three subjects submitted to both brief and prolonged accelerations. In each case the pressures remained subzero throughout the acceleration. Brief accelerations of abrupt onset gave the most marked pressure falls and records showing the highest and lowest values obtained with such runs are presented. In the third subject the results were intermediate but of an identical pattern. In one run the arterial and jugular pressures were recorded during a 30 second acceleration (Figure 3 ). Seven seconds after the initial fall in arterial pressure, the vasopressor response took effect and the arterial pressure recovered to some extent. The first and third interrupted lines below the venous pressure curve, respectively, register response to peripheral and central lights (24). This case lost his peripheral lights for 3.5 seconds at a mean arterial pressure

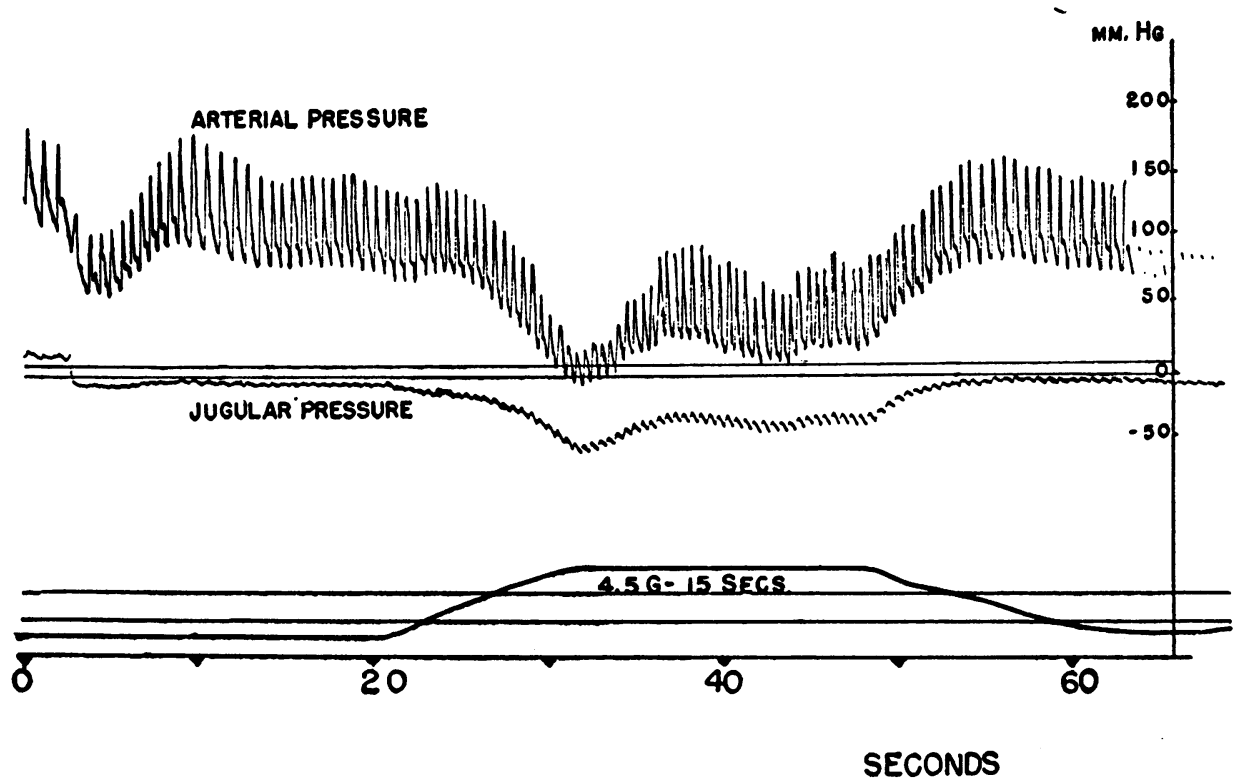

Fig. 4. Cerebral Arterial and Jugular Venous Pressures during a 4.5 g, 15 Second Run, Showing the Continued Retention of a High Arterio-Venous Pressure Difmerential Due to a Marked Fall in Jugular Pressure during the Acceleration 
of 10 to $15 \mathrm{~mm} . \mathrm{Hg}$, then during the vasopressor response, the mean arterial pressure rose to $50 \mathrm{~mm}$. $\mathrm{Hg}$ and stabilized at $35 \mathrm{~mm}$. $\mathrm{Hg}$. The jugular pressure fell to $20 \mathrm{~mm}$. Hg negative pressure at the time of the greatest fall in arterial pressure. Later, as the arterial pressure rose, the jugular pressure became less negative but still remained $8 \mathrm{~mm}$. $\mathrm{Hg}$ less than ambient. At critical levels of cerebral arterial pressure, this addition could represent the difference between unconsciousness and adequate responses (see Table I).

In another case the jugular suction effect was much greater (Figure 4), and the fall was momentarily approximately $60 \mathrm{~mm}$. Hg. Although the mean arterial pressure was less than $10 \mathrm{~mm}$. $\mathrm{Hg}$ for three to four seconds, and less than $30 \mathrm{~mm}$. $\mathrm{Hg}$ for more than six seconds, only mild visual dimming occurred. This may be because the venous pressure followed the arterial pressure changes and the cerebral arterio-venous pressure differential was never less than $50 \mathrm{~mm}$. $\mathrm{Hg}$. It was noted that whenever the onset of the acceleration was gradual, the magnitude of the jugular pressure fall was far less. A possible explanation for this will be advanced in the discussion.

\section{DISCUSSION}

These experiments demonstrate that there is some mechanism which compensates for the fall in cerebral arterial pressure induced by gravitational stress. Scheinberg and Stead (18) have also observed that when tilting patients into the erect posture, the fall in arterial pressure induced by gravity stress was of greater extent than that of the cerebral blood flow. They too, point out that the apparent fall in cerebral vascular resistance could either be due to a mechanical pressure decrease on the venous side of the capillary bed, or to active cerebral vasodilation. An additional effect could be a passive dilation of the brain vessels brought about by a fall in venous pressure. It is possible that all of these mechanisms may be in operation at the same time.

When the stress is imposed rapidly, the ensuing subatmospheric pressures which have been demonstrated in the jugular bulb of men and the saggittal sinus of cats and dogs $(25,7)$ are produced almost instantaneously. Any active dilation mediated through the nervous system would require several seconds. Not only does the subatmospheric pres- sure effect develop rapidly, but also it is sufficiently intense to account for the continued blood flow and high venous oxygen saturation, in a large part. However, at no time is it large enough to completely balance the fall in arterial pressure. Even in the case shown in Figure 4, the arteriovenous pressure differential sinks approximately to one half of its normal value during the run. The fact that cerebral vascular sufficiency, as indicated by the cerebral arterio-venous oxygen difference, is hardly affected by such a marked fall in the driving pressure makes it probable that the flow is sustained by a decrease in cerebral vascular resistance which assists the direct pull of the venous pressure fall.

There is a purely mechanical means by which such a fall in resistance may be brought about by a pressure decrease on the venous side of the capillary bed. A drop in pressure in the venous plexus about the spinal cord during acceleration in the upright seated posture would lead to collapse of these veins by drainage into the lower abdominal system. This space left by them would be filled by cerebro-spinal fluid draining from the cranial cavity. Thus a passive distension of the cerebral vessels might occur to fill the gap left by the cerebro-spinal fluid. During the distension of the veins a small amount of blood will be aspirated from the arterial tree. It was this brief excess of blood flow that Ranke (26) and others (25) believed might play some part in preventing loss of consciousness during short-lasting accelerations. For it has long been known that venous and cerebro-spinal fluid pressure in the head becomes negative in man when he assumes the erect posture (27). Ranke (26), Jasper and Cypriani (28), and Rushmer, Beckman and Lee (25) also recognized that in animals these pressures become strongly subatmospheric during positive acceleration. It has not been generally realized that significant deep channels, which can remain patent in spite of subatmospheric pressures, are available for the return of blood from the brain. Nor, as a matter of fact, has the partition into the various available channels of the blood returning during acceleration yet been analyzed.

It is now appreciated that the internal and external vertebral venous plexes (29) are extensive and the internal system is protected from collapse during acceleration by the subatmospheric cere- 
bro-spinal fluid pressure (25). Therefore, an uninterrupted flow can continue down these vessels. The fact that edema of the face has been reported following blocking of the superior vena cava suggests that in man the capacity of the subsidiary channels is limited and that extra pressure is needed to force the full cerebral blood flow through them (30). Thus any rise in arterial pressure, or active or passive vasodilatation tending to increase blood flow during acceleration would be partially offset by a rise in pressure in the jugular bulb. When the pressure in this region becomes atmospheric, then it may be assumed that the jugular veins become available and the resistance to flow would fall accordingly. Such a mechanism would explain the simultaneous fluctuations of arterial and venous pressures observed in these records. For, as arterial pressure fell and flow decreased, the pressure in the jugular bulb at the entrance to the cervical venous system would fall and the venous pull would increase correspondingly. It also explains why when the gravitational stress is imposed slowly and there is adequate time for a vasopressor response, the fall in jugular pressure is far less pronounced than during the first few seconds after an abrupt acceleration when the fall in cerebral arterial pressure is most marked.

The increased pulsation in the jugular tracing during the acceleration would suggest a vasodilatation (Figures 3 and 4). These waves do not originate from the auricle and are not transmitted up to the jugular vein, for they are not eliminated by manual occlusion of the vein during acceleration. They might be due to the direct transmission of the arterial pulse through passively dilated cerebral vessels. Alternatively, the venous pulsations may be due to direct transmission of volume changes from arteries to veins across the tissues of the brain. The pulsations would become more intense when the cerebral arterial pressure decreased during the acceleration because the arteries are not then so completely distended and would, therefore, fluctuate in volume more at any given pulse pressure.

There is some evidence of active cerebral vasodilatation during acceleration. Thus it was found that the cerebral venous oxygen saturation in anesthetized animals exposed to positive acceleration remained elevated for several minutes after the run in spite of normal arterial pressures (31). It is of interest in this connection that of the two $1 \mathrm{~g}$ controls in the series identified by the squares in Figure 1, the higher value of $57.2 \%$ was for blood taken immediately after a series of prolonged runs. However, data such as these can, at best, only be regarded as suggestive. Fortunately, Kety and his associates (14) have recently shown that when in hypertensives, the blood pressure is reduced by spinal sympathetic block, there is a partial relaxation of the cerebral vessels which tends to counteract the decrease in cerebral flow which would otherwise occur. This reflex relaxation does not compensate as fully for the fall in blood pressure as do the various mechanical and nervous factors at play during gravitational stress. This can be seen by comparing Figure 1 in their article with Figure 1 in the present article. A reduction of the arterial pressure to one half its normal value has less influence upon the venous oxygen saturation in the cases undergoing acceleration. When contrasted with the results of gravity induced cerebral hypotension, the data of Kety's group throw light upon the relative roles played by mechanical factors and by active cerebral vascular relaxation in the determination of cerebral blood flow, always provided that such relaxation also occurs in normal persons. Also the observation that relaxation of the cerebral vessels appeared to be independent of the degree of hypertension does suggest that a similar relaxation may occur in normotensive individuals suffering a sudden fall in blood pressure.

If the arterial pressure falls below the value necessary to force the blood to head level and hold open the carotid vessels and the cerebral vascular bed, then unconsciousness will occur no matter how perfect the compensation provided by suction and other factors. Animal experiments (31) have suggested that at high accelerations, when the pressure falls too low to fill the carotid arteries up to the level of the base of the brain, they collapse and flow through the carotid system ceases abruptly. Although in the dog the remaining flow through the pressure protected vertebral and spinal vessels may be adequate to maintain consciousness $(5,32)$, in man this is not so. Consequently, in contrast with the dog $(31)$, in man consciousness is lost when arterial pressures at head level become subzero. 
The fact that slightly higher blood pressures are required to maintain vision when protection against the effects of acceleration is afforded by pneumatic anti-G suits (33) may be due to the increase in central venous pressure and in cerebralspinal fluid pressure produced by the inflation of such suits.

Ernstene and Blumgart (34) have suggested that one of the reasons for the orthopnoea of congestive heart failure might be an improvement in the cerebral circulation that resulted from the lowering of the cerebral venous pressure in the erect position. It is possible that some significance should be attached to this factor $(35,36)$. Certainly, the evidence just presented has shown that when a subject is placed in the erect position in a high gravitational field, the cerebral vascular sufficiency may remain undisturbed in spite of a great fall in arterial pressure. It is not yet clear whether this occurs solely as a direct result of the decrease in pressure on the venous side of the cerebral capillaries or whether passive vasodilatation also occurs due to an expansion of the cerebral vascular bed, but it is probable that whenever the acceleration persists for more than a few seconds, a combination of these effects develops, together with some active cerebral vasodilatation.

\section{SUMMARY}

1. Consciousness is usually lost when the mean cerebral blood pressure falls to $25 \mathrm{~mm}$. $\mathrm{Hg}$, but during exposure to high accelerations such as those producing aviator's blackout, alertness may be retained in spite of such mean pressures.

2. Arterial and cerebral venous oxygen saturation and arterial pressure at head level and cerebral venous pressures were measured in three subjects during acceleration. The venous saturation remained almost unchanged in spite of great falls in cerebral arterial pressure. This suggested that some factor was maintaining cerebral blood flow.

3. Pressures ranging from 20 to $60 \mathrm{~mm}$. Hg below ambient were found in the jugular bulb. This effect could maintain consciousness by sustaining the arterio-venous pressure differential, or by producing a combination of such an effect with passive cerebral vasodilatation.

4. There is also evidence that active cerebral vasodilatation may occur during prolonged exposure to gravitational stress in the erect posture.

\section{ACKNOWLEDGMENTS}

The authors would like to express their appreciation to Mr. E. E. Martin for his participation in these experiments and to Dr. Earl Wood for his comments on the manuscript.

\section{REFERENCES}

1. Lambert, E. H., Hallenbeck, G. A., Baldes, E. J., Wood, E. H., and Code, C. F., The symptoms which occur in man during exposure to positive acceleration. Federation Proc., 1945, 4, 43.

2. Lambert, E. H., The physiologic basis of "blackout" as it occurs in aviators. Federation Proc., 1945, 4, 43.

3. Lambert, E. H., and Wood, E. H., Direct determination of man's blood pressure on the human centrifuge during positive acceleration. Federation Proc., 1946, 5, 59.

4. Wood, E. H., Personal communication.

5. Rossen, R., Kabat, H., and Anderson, J. P., Acute arrest of the cerebral circulation in man. Arch. Neurol. \& Psychiat., 1943, 5, 510.

6. Clark, W. G., MacIntyre, A. K., and Gardiner, I. R., Effect of positive acceleration on fluid loss from the blood to tissue spaces in a human subject on the centrifuge. Nat. Res. Council, CAM Report, 1945, No. 468.

7. Henry, J. P., Gauer, O. H., and Martin, E. E., Unpublished data.

8. Ellis, L. B., and Haynes, F. W., Postural hypotension with particular reference to its occurrence in disease of the central nervous system. Arch. Int. Med., 1936, 58, 773.

9. Jeffers, W. A., Montgomery, H., and Burton, A. C., Types of orthostatic hypotension and their treatment. Am. J. M. Sc., 1941, 202, 1.

10. Gregory, R., Treatment of orthostatic hypotension with particular reference to the use of desoxycorticosterone. Am. Heart J., 1945, 29, 246.

11. McMicheal, J., Clinical aspects of shock. J.A.M.A., 1944, 124, 275.

12. Loman, J., Dameshek, W., Myerson, A., and Goldman, $D$., The effect of alterations in posture on intra-arterial blood pressure in man; pressure in the carotid artery in arteriosclerosis during syncope and after the use of vasodilator drugs. Arch. Neurol. \& Psychiat., 1936, 35, 1225.

13. Rushmer, R. F., Physiology of intrathoracic pressures in relation to centrifugal forces. Neurogenic peripheral circulatory failure. Project 160, Rpt. No. 4, USAAF School of Aviation Medicine, 1944, 1 Aug.

14. Kety, S. S., King, B. D., Horvath, S. M., Jeffers, W. A., and Hafkenschiel, J. H., The effects of acute reduction in blood pressure by means of differential spinal sympathetic block on the cerebral circulation of hypertensive patients. J. Clin. Invest., 1950, 29, 402. 
15. Descriptive data and operating instructions; Statham Physiological Pressure Transducers. Bulletin No. 3.13.

16. Henry, J. P., Greeley, P. O., Fryckman, V. L., and Peterson, L., An indwelling arterial needle for use in the radial artery. Science, 1946, 104, 299.

17. Starling, E. H., Principles of Human Physiology. Lea \& Febiger, Philadelphia, 1933, Ed. 6, p. 809.

18. Scheinberg, P., and Stead, E. A., Jr., Cerebral blood flow in male subjects as measured by nitrous oxide technique. Normal values for blood flow, oxygen utilization, glucose utilization and peripheral resistance with observations on the effect of tilting and anxiety. J. Clin. Invest., 1949, 28, 1163.

19. Myerson, A., Halloran, R. D., and Hirsch, H. L., Technique for obtaining blood from the internal jugular vein and internal carotid artery. Arch. Neurol. \& Psychiat., 1927, 17, 807.

20. Kety, S. S., Quantitative determination of cerebral blood flow in man, in Methods in Medical Research, V. R. Potter, Editor. Year Book Publishers, Chicago, Ill., 1948, Ed. 1, Vol. 1, p. 204.

21. Van Slyke, D. D., and Neill, J. W., Determination of gases in blood and other solutions by vacuum extraction and manometric measurement. J. Biol. Chem., 1924, 61, 523.

22. Kramer, K., Monograph on German Aviation Medicine. School of Aviation Medicine, Randolph A. F. B., Texas, 1950, Vol. 1, p. 160.

23. Strand, O. T., Remotely controlled blood extractor. USAAF Materiel Command Memo. Rpt. MCREXD-695-74H, 1948, April.

24. Maaske, C. A., Maison, G. L., and Martin, E. E., Description of the Materiel Command human centrifuge; techniques employed therewith and results of normal $\mathbf{g}$-tolerance in human subjects. USAAF
Materiel Command Memo. Rpt. No. ENG-49-6964D, 1943, 1 Oct.

25. Rushmer, R. F., Beckman, E. L., and Lee, D., Protection of cerebral circulation by the cerebrospinal fluid under the influence of radial acceleration. Am. J. Physiol., 1948, 151, 355.

26. Ranke, O., Beschleunigungswirkung. Luftfahrtmedizin, 1938, 2, 243.

27. Hill, L., Influence of gravity upon the circulation. J. Physiol., 1895, 18, 15.

28. Jasper, H., and Cypriani, A., Personal communication.

29. Morris, H., Morris' Human Anatomy: A Complete Systematic Treatise. Blakiston, Philadelphia, 1942, Ed. 10, p. 728.

30. Batson, O. V., Anatomical problems concerned in the study of cerebral blood flow. Federation Proc., 1944, 3, 139.

31. Henry, J. P., and Gauer, O. H., Unpublished data.

32. Dennis, C., and Kabat, H., Behavior of dogs after complete temporary arrest of cephalic circulation. Proc. Soc. Exper. Biol. \& Med., 1939, 40, 559.

33. Wood, E. H., and Lambert, E. H., The effect of antiblackout suits on blood pressure changes produced on the human centrifuge. Federation Proc., 1946, $5,115$.

34. Ernstene, A. C., and Blumgart, H. L., Orthopnea, its relation to increased venous pressure of myocardial failure. Arch. Int. Med., 1930, 45, 593.

35. Schmidt, C. F., Abnormal types of respiration in McLeod's Physiology in Modern Medicine, P. Bard, Editor. C. V. Mosby, St. Louis, 1941, Ed. 9, Part 4, p. 655.

36. Altschule, M. D., Physiology in Diseases of the Heart and Lungs. Harvard University Press, Cambridge, 1949, Ed. 1, p. 175. 